\title{
A generalized sample preparation method by incorporation of metal-organic compounds into polymers for electroless metallization
}

Atilla Atli, ${ }^{1}$ Francisco J. Cadete Santos Aires, ${ }^{3,4}$, Vanessa Trouillet, ${ }^{2}$ Eric Ehret, ${ }^{3}$ Etienne Lemaire, ${ }^{1}$ Sandra Simon ${ }^{1}$

\author{
${ }^{1}$ Université de Lyon, ECAM Lyon, LabECAM, F-69005 Lyon, France \\ ${ }^{2}$ Institute for Applied Materials (IAM) and Karlsruhe Nano Micro Facility (KNMF), Karlsruhe Institute \\ of Technology (KIT) 76344 Eggenstein- Leopoldshafen Germany \\ ${ }^{3}$ IRCELYON (UMR 5256 CNRS/UCB Lyon 1), Université de Lyon, Villeurbanne, 69100, France \\ ${ }^{4}$ Laboratory of Catalytic Research, National Research Tomsk State University, Tomsk, 634050, Russia \\ Correspondence to: Atilla Atli (E-mail: atilla.atli@ecam.fr)
}

\begin{abstract}
Metallization of polymers is important for several technological and industrial applications. In this work, we demonstrate the influence of metallization bath parameters on LCP Vectra ${ }^{\circledR} 820$ i polymer samples prepared by incorporation of a small amount $(<0.5 \mathrm{wt} \%)$ of metal-organic compounds (palladium, nickel or copper acetates) in the molten polymer. During blending, the acetates thermally decompose and yield the metallic particles ( $\mathrm{Pd}, \mathrm{Ni}$ or $\mathrm{Cu}$ ) which are used as the activators for electroless copper deposition. After surface preparation, copper is deposited on LCP Vectra ${ }^{\circledR} 820 \mathrm{i}$ in an electroless bath including formaldehyde as reducer. The influence of metallization bath temperature and bath composition with respect to the copper deposition is investigated. The initiation of copper deposition is delayed for lower temperatures. In the temperature range of $35^{\circ} \mathrm{C}$ $55^{\circ} \mathrm{C}$, after $60 \mathrm{~min}$ of deposition, the amount of deposited copper is similar for $35^{\circ} \mathrm{C}, 40^{\circ} \mathrm{C}$ and $45^{\circ} \mathrm{C}$, and higher than that at $50^{\circ} \mathrm{C}$ and $55^{\circ} \mathrm{C}$. The maximum rate of copper deposition is around $60 \mu \mathrm{g} \mathrm{cm}^{-2}$ $\min ^{-1}$ for $35^{\circ} \mathrm{C}, 40^{\circ} \mathrm{C}$ and $45^{\circ} \mathrm{C}$ and higher than $50^{\circ} \mathrm{C}$ and $55^{\circ} \mathrm{C}$. The mean diameter of deposited copper particles shifts to smaller values with increasing bath temperature. When the formaldehyde volume is increased in the metallization bath, the maximum deposition rate is higher, shifts to shorter deposition time and the mean particle diameter becomes smaller. The metallization reaction order with respect to formaldehyde and the activation energy of electroless copper deposition decreases with increasing deposited copper amount.
\end{abstract}




\section{INTRODUCTION}

The metallization of polymers is important for several industrial and technological applications [1], [2]. Liquid Crystal Polymer (LCP Vectra ${ }^{\circledR}$ E820i) is a high performance thermoplastic polymer and combines several interesting properties, like low moisture absorption, high heat resistance, high chemical and mechanical resistances, low coefficient of thermal expansion, low dielectric constant, excellent flow properties and dimensional stability [3]. These assets can be combined for numerous applications ones it is metallized: in microelectronics for packaging [4], Microelectromechanical Systems (MEMS) [5] [6] and Molded Interconnect Devices (MIDs) [7].

The electrolytic process cannot be employed on non-conductors like polymers for their metallization. The electroless metal deposition is commonly used industrial processes on polymer surfaces [8] [9] due to its low cost, simple processing, uniform deposition layer on large surfaces, low temperature treatment and no requirement of vacuum system [10] [11]. Once a metal with enough thickness is electroless deposited on polymer surface, the electrolytic deposition can be further processed onto the electroless metal layer. Among the metals, copper is widely used metal in electrical connections associating low electrical resistivity, high electro migration resistance [12] and low-cost.

The traditional electroless copper deposition process on polymers involves commonly three steps: surface preparation/modification, surface activation (sensitizing or seeding), and electroless copper deposition [13]. The first step enables cleaning and modification of polymer surface in order to improve the adhesion of the forthcoming electroless metal layer. Several methods have been employed for this purpose including plasma surface modification [14] [15], laser treatment [16], surface grafting [17] [18], silane modification [19] and chemical etching [20]. The principal advantages of the chemical etching process are its low cost, simplicity and easy application without sophisticated tools. After carrying out the chemical etching, it is possible to produce the micro cavities and then increase the surface roughness. Such a rough surface favors the mechanical interlocking of the electroless deposited copper particles. 
The activation step permits to apply an appropriate catalyst on polymer surfaces. These catalysts (activators) which are mainly transition metals [8] [21] [22] [23] [24] initiate the metal deposition. Among the transition metals, palladium is a commonly utilized catalyst for activating the electroless metal plating process [25]. The most common industrial method is the use of $\mathrm{SnCl}_{2}$ and $\mathrm{PdCl}_{2}$ solutions or mixed $\mathrm{Sn} / \mathrm{Pd}$ colloids where the metallic palladium seed is deposited on a polymer surface after reaction with $\mathrm{Sn}(\mathrm{II})$. However, the high cost of palladium forces its replacement with cheaper metals. Different processes have been performed for applying these catalysts on the polymer surfaces. But these methods sometimes need several steps [26] [27] [28] [29] [30] [31] and modern set-up. For example, a thin palladium acetate/acetone film was deposited on polyimide surfaces, then illuminated by an UV lamp and irradiated by a laser beam for patterning [27]. Copper was coated on PET films by using a silver mask exposed to oxygen plasma treatment [32]. Byeon et al. [28] have deposited copper on a palladium aerosol activated polymer membrane in the presence of ultrasounds. Zhou et al. [33] have prepared the polymer samples by mixing the polycarbonate (PC) with copper powder. After injection of the mixture as plates, they have activated samples by a 1064 $\mathrm{nm}$ laser beam and have deposited the electroless copper on the sample surface. A cheap and simple method to prepare polymer samples by incorporation of a small amount of metal-organic compounds (acetates of palladium, nickel or copper) in LCP Vectra ${ }^{\circledR}$ E820i polymer has been demonstrated [34]. During blending, since polymer was kept at sufficiently high temperature, the acetates were thermally decomposed resulting the metallic particles of $\mathrm{Pd}, \mathrm{Ni}$ and $\mathrm{Cu}$ that are used as catalysts for electroless deposition [34].

The third step is the electroless deposition of copper in a bath containing a salt of copper and a reducing agent. This electroless metallization reaction is spontaneous since $\mathrm{Cu}^{2+}$ is reduced to $\mathrm{Cu}$ by the reducing agent (frequently formaldehyde, $\mathrm{HCHO}$ ) on the active sites obtained during the activation step on polymer surfaces. This spontaneous reaction is initiated by the activator that lowers the activation energy for metal plating [35]. 
Electroless copper deposition on metal-organic compounds ( $\mathrm{Pd}, \mathrm{Ni}$ or $\mathrm{Cu}$ acetates) incorporated LCP Vectra ${ }^{\circledR}$ E820i samples has been previously investigated for a fixed composition of metallization bath at $45^{\circ} \mathrm{C}$ [34]. In this previous work, the electroless copper deposition on $0.15 \mathrm{wt} \% \mathrm{Pd}$ incorporated LCP Vectra ${ }^{\circledR}$ E820i was more efficient compared to the deposition on 0.4 wt $\% \mathrm{Ni}$ and $0.4 \mathrm{wt} \% \mathrm{Cu}$ incorporated LCP Vectra ${ }^{\circledR}$ E820i, even the Pd amount was smaller [34]. In this work, we then studied the influence of bath temperature and bath composition on the most efficient samples i.e. palladium acetate incorporated LCP Vectra ${ }^{\circledR}$ E820i in order to optimize the electroless copper deposition process. The incorporated final Pd amount was around $0.15 \mathrm{wt} \%$ as measured by Inductively Coupled Plasma Mass Spectrometry (ICP-MS). The metallization bath included commercial ENPLATE LDS Cu100, deionized water and 37\% diluted formaldehyde (used as reducing agent) with a typical ratio of $40 \mathrm{~mL}: 160 \mathrm{~mL}: 2 \mathrm{~mL}$, respectively. The influence of composition (formaldehyde concentration) and temperature of the metallization bath on the copper deposition process is studied. The deposited copper amount was measured by weighing samples with a micro balance. The evolution of electroless copper amount and copper deposition rate with time is studied as a function of metallization bath temperature and formaldehyde volume. The size distribution of the electroless deposited copper particles was also studied for different parameters from Scanning Electron Microscope (SEM) images.

\section{EXPERIMENTAL}

Materials and sample preparation method have been detailed elsewhere [34]

\section{Materials}

LCP Vectra ${ }^{\circledR}$ E820i, a special grade of LCP with $40 \%$ mineral filler is provided from Celanese.

Palladium is purchased from Acros Organics with a purity of $99.9 \%$.

The conditioner PM-925 from Dow Chemicals was employed for polymer etching. It is an alkaline solution, with a pH around 13 and includes $\mathrm{KOH},[34]$. The commercial ENPLATE LDS Cu100 product (from Enthone Company) was used for the preparation of the electroless copper metallization bath. 
The supplier indicates that this solution contains copper sulfate and sodium hydroxide. It probably also includes ethylenediaminetetraacetic acid (EDTA) as complexing agent in order to avoid the copper precipitation [34].

\section{Sample preparation}

The samples were prepared by blending the commercially available LCP Vectra ${ }^{\circledR}$ E820i pellets with acetate of palladium as detailed previously [34]. The initial palladium acetate mass fraction was calculated in a way that the final metal particle amount remains very small. A very small amount of acetate incorporation is preferred, not only for the price of palladium but, particularly, to avoid the drastic modification of some polymer properties (mechanical, electrical, thermal).

The polymer pellets were dried in a furnace at $170^{\circ} \mathrm{C}$ during 8 hours before blending. The polymer and palladium acetate blend was prepared in a Brabender blender at $360^{\circ} \mathrm{C}$. The acetate of Pd was gradually added into the molten LCP Vectra ${ }^{\circledR}$ E820i previously put in the mixer bowl of $35 \mathrm{~cm}^{3}$ in volume. The torque generated by two rotating blades with adjustable speed was recorded as a function of time during blending and the blades were kept at constant torque for approximately 10 min once the torque was stabilized. Three to four batches yielded enough material to inject a dozen samples. After preparation of blend, the obtained pads were grinded and injected as small rods of 4 $\mathrm{mm} \times 10 \mathrm{~mm} \times 100 \mathrm{~mm}$ by using an ARBOURG AllRounder 270S injection mold with a screw of $18 \mathrm{~mm}$ in diameter. The typical temperatures during injection molding were $335-350{ }^{\circ} \mathrm{C}$, with the mold temperature set to $80^{\circ} \mathrm{C}$. The injection pressure was 1800 bars with an injection time around 10 seconds.

0.15 wt \% Pd incorporated LCP Vectra ${ }^{\circledR}$ E820i samples were prepared and labelled as LCP-0.15 w\% Pd The initial mass of metal-organic compound was calculated in a way that the final mass fraction was 0.15 wt \% of Pd. 
Palladium acetate was selected in relation with the melting and degradation temperatures of polymer. Precisely, the thermal decomposition temperature of palladium acetate should be higher than the melting temperature of polymer but lower than its degradation temperature. In such a way, palladium acetate can be thermally decomposed into the molten polymer during blending of polymer-acetate mixture. The melting temperature of LCP Vectra ${ }^{\circledR} 820 \mathrm{i}$ is $335^{\circ} \mathrm{C}$ after the technical datasheet of supplier [36]. The decomposition temperature of palladium acetate in air is in the range of $214-276^{\circ} \mathrm{C}$ depending on the heating rate as analyzed by TGA [37]. The TGA experiment has been performed in air while in our case the Pd acetate was decomposed in a polymer environment (LCP Vectra $\left.{ }^{\circledR} \mathrm{E} 820 \mathrm{i}\right)$. The environment can modify the decomposition route and the final products. It was supposed that the palladium acetate was decomposed during the blending process yielding some metallic active sites for electroless Cu deposition.

\section{Bath conditions}

Three main steps were employed in the electroless copper deposition process: etching, neutralization and metallization. After each main step, an intermediate rinsing bath with deionized water was employed. Deionized water was also used to prepare all the baths.

The PM-925 product was used as a first cleaning/etching step for the surface treatment of LCP Vectra ${ }^{\circledR}$ E820i at $82{ }^{\circ} \mathrm{C}$ for $8 \mathrm{~min}$. The etching process improves the mechanical adhesion of deposited copper by increasing the roughness of the polymer surface. The bath was slowly stirred with a polytetrafluoroethylene (PTFE) covered magnetic stirrer. After etching, the samples were rinsed in a deionized water bath at $50^{\circ} \mathrm{C}$ followed by another deionized water bath at room temperature.

The neutralization step was performed by dipping the samples during 5 minutes into a neutralization bath including diluted sulfuric acid ( $5 \mathrm{vol} \%)$ and deionized water. The $\mathrm{pH}$ of the neutralization bath was 5.5. The aim of this step is to remove the traces of alkaline PM-925 in the first etching step. A fast stirring of the bath is employed. After neutralizing, the samples were rinsed in deionized water and dried by compressed air. 
The electroless copper deposition bath was prepared by using ENPLATE LDS Cu100, deionized water and $37 \%$ diluted formaldehyde with appropriate volume proportion. The typical metallization bath volume was around $200 \mathrm{~mL}$ including thus $40 \mathrm{~mL}: 160 \mathrm{~mL}: 2 \mathrm{~mL}$ of ENPLATE LDS Cu100, deionized water and formaldehyde respectively (volume proportion of 20:80:1). The $\mathrm{pH}$ of the metallization bath was around 12 . The usual bath temperature was $45^{\circ} \mathrm{C}$. Moreover the influence of the bath composition and bath temperature on the electroless copper deposition process was investigated. The formaldehyde proportion was varied from $1 \mathrm{~mL}$ to $6 \mathrm{~mL}(1 \mathrm{~mL}, 1.5 \mathrm{~mL}, 2 \mathrm{~mL}$ and $6 \mathrm{~mL}$ ) while the ENPLATE LDS Cu100 and deionized water amount set fixed $(40 \mathrm{~mL}$ and $160 \mathrm{~mL}$ respectively, i.e. a ratio of $20: 80: 1$ to $20: 80: 3$ ) in the metallization bath kept at $45^{\circ} \mathrm{C}$. In the case of the fixed metallized bath composition including $40 \mathrm{~mL}$ of ENPLATE LDS Cu100, $160 \mathrm{~mL}$ of deionized water and $2 \mathrm{~mL}$ of formaldehyde (proportion 20:80:1), the metallization of LCP-0.15 wt \% Pd samples was studied with different bath temperatures changing from $35^{\circ} \mathrm{C}$ to $55^{\circ} \mathrm{C}\left(35^{\circ} \mathrm{C}, 40^{\circ} \mathrm{C}, 45^{\circ} \mathrm{C}, 50^{\circ} \mathrm{C}\right.$ and $\left.55^{\circ} \mathrm{C}\right)$. The metallization bath was not stirred during the metallization process.

During a metallization experiment, the sample was dipped into the metallization bath and was taken off after some metallization time for weighing then put again in the same metallization bath. Since the samples can retain some residue of etching or neutralization bath, which can destroy the subsequently deposited copper layer over time, the samples were thoroughly rinsed in deionized water, dried by compressed air and weighed. The final rinsing and drying steps are necessary in order to have a dry sample before the sample mass gain measurements. The metallization bath was not renewed during a metallization experiment.

\section{Sample characterization}

The samples were characterized as discussed elsewhere [34].

The samples were weighed by a Mettler AE166 Delta range microbalance in order to determine the electroless deposited copper amount. 
The amount of Pd was around $0.15 \mathrm{wt} \%$ in LCP as measured by ICP-MS technique carried out in an external subcontracted laboratory.

A Philips XL30i Scanning Electron Microscope (SEM) was used for the observation of the deposited copper particles on LCP Vectra ${ }^{\circledR}$ E820i sample surfaces.

\section{RESULTS AND DISCUSSION}

Some results on the metallization of $\mathrm{Pd}, \mathrm{Ni}$ and $\mathrm{Cu}$ incorporated LCP Vectra ${ }^{\circledR}$ E820i have been presented elsewhere [34]. As said previously, the LCP-0.15 wt \% Pd sample was more efficient for electroless copper deposition compared to LCP-0.4 wt \% Ni and LCP-0.4 wt \% Cu, even though the palladium amount was smaller.

In the present work, we then investigated the influence of the metallization bath temperature and bath composition on the electroless deposition of copper on LCP-0.15 wt \% Pd samples for optimizing the electroless process.

Two series of electroless copper deposition experiments were carried out on 0.15 wt \% Pd filled LCP Vectra ${ }^{\circledR}$ E820i samples. The first series of metallization was performed in the metallization baths with different temperatures $\left(35^{\circ} \mathrm{C}, 40^{\circ} \mathrm{C}, 45^{\circ} \mathrm{C}, 50^{\circ} \mathrm{C}\right.$ and $\left.55^{\circ} \mathrm{C}\right)$ by keeping the bath in a fixed composition (40 mL of ENPLATE LDS Cu100, $160 \mathrm{~mL}$ of deionized water and $2 \mathrm{~mL}$ of formaldehyde i.e. a proportion 20:80:1). The second series of experiments were realized in a metallization bath with different volumes of formaldehyde $(1 \mathrm{~mL}, 1.5 \mathrm{~mL}, 2 \mathrm{~mL}$ or $6 \mathrm{~mL}$ formaldehyde poured in $40 \mathrm{~mL}$ of ENPLATE LDS Cu100 and $160 \mathrm{~mL}$ of deionized water) by keeping the bath temperature at $45^{\circ} \mathrm{C}$.

\section{Electroless copper deposition on LCP-0.15 wt\% Pd with different bath temperatures}

Figure 1 shows the LCP-0.15wt \% Pd samples with different copper deposition temperatures. The deposited copper was at the bottom part of the rod shaped samples. 


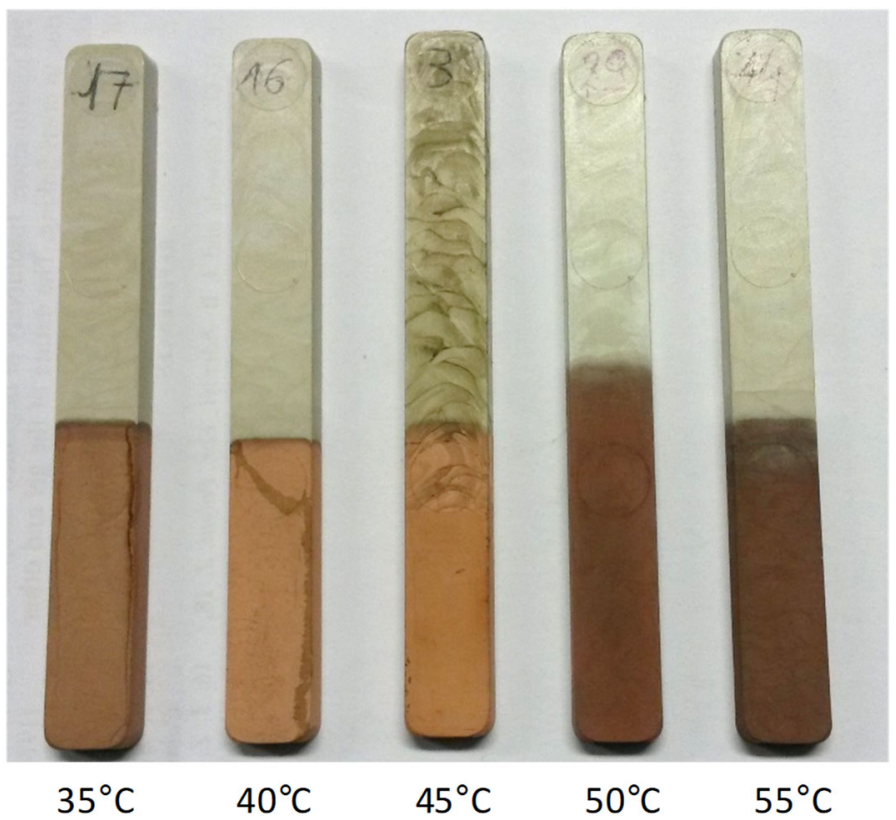

Figure 1. Copper deposition on LCP-0.15 wt \% Pd samples at different bath temperatures (from left to right: $\left.35^{\circ} \mathrm{C}, 40^{\circ} \mathrm{C}, 45^{\circ} \mathrm{C}, 50^{\circ} \mathrm{C}, 55^{\circ} \mathrm{C}\right)$.

The amount of deposited copper on LCP-0.15wt \% Pd samples was plotted as a function of cumulative dipping time into the metallization bath at: $35^{\circ} \mathrm{C}, 40^{\circ} \mathrm{C}, 45^{\circ} \mathrm{C}, 50{ }^{\circ} \mathrm{C}$ and $55^{\circ} \mathrm{C}$ (Figure 2 ).

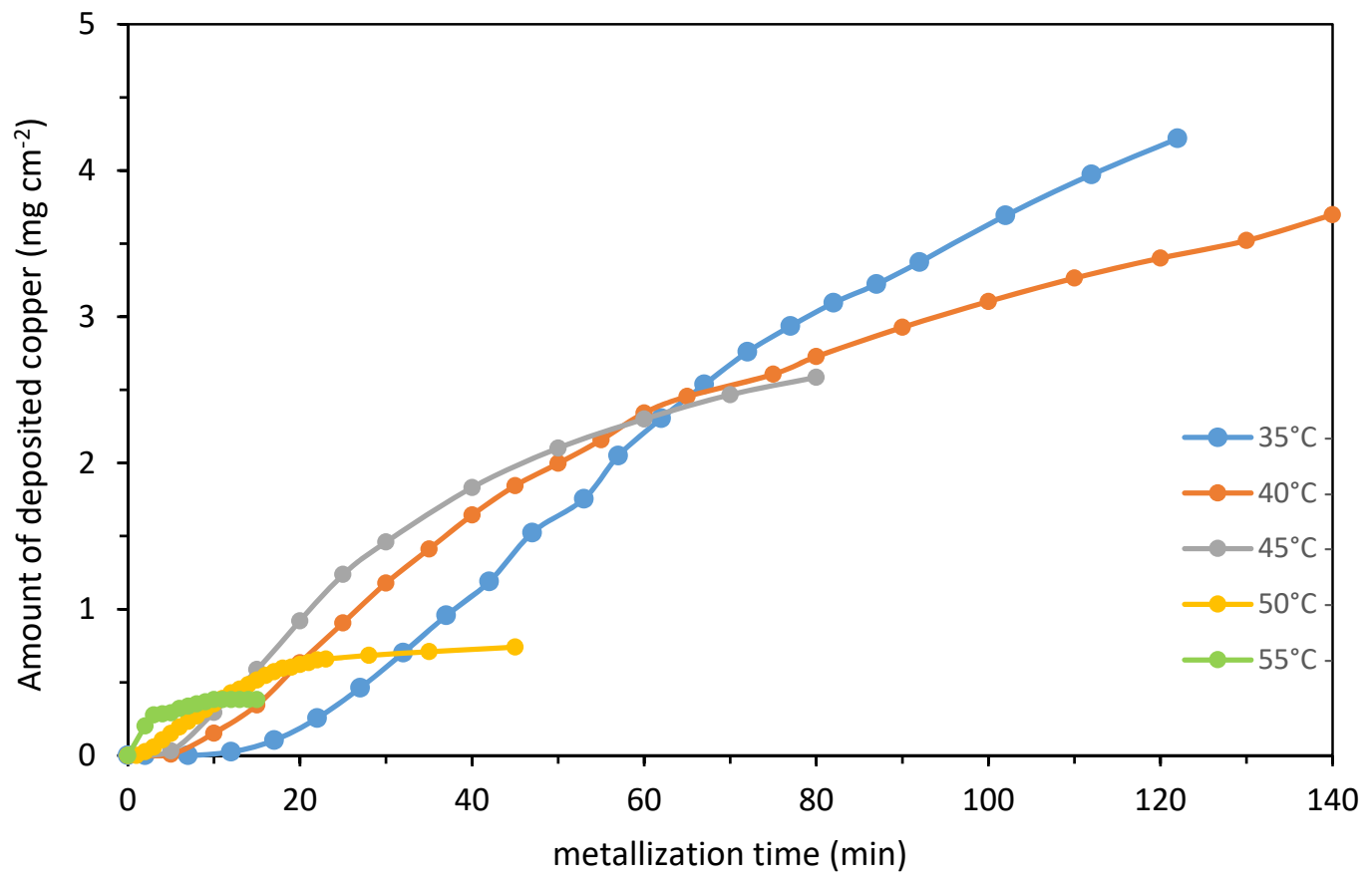


Figure 2. Amount of deposited copper per unit area $\left(\mathrm{mg} \mathrm{cm}^{-2}\right)$ on LCP-0.15 wt \% Pd samples as a function of cumulative dipping time into the metallization bath kept at different temperatures: $35^{\circ} \mathrm{C}$, $40{ }^{\circ} \mathrm{C}, 45^{\circ} \mathrm{C}, 50^{\circ} \mathrm{C}$ and $55^{\circ} \mathrm{C}$.

The deposited Cu amount initially increases with time for all temperatures and arrives rapidly to a plateau for $50{ }^{\circ} \mathrm{C}$ and $55^{\circ} \mathrm{C}$ on LCP- 0.15 wt \% Pd samples. The amount of deposited copper at the end of the experiment at $50{ }^{\circ} \mathrm{C}$ and $55^{\circ} \mathrm{C}$ is relatively low, compared to the deposition at lower temperatures $\left(35^{\circ} \mathrm{C}, 40^{\circ} \mathrm{C}\right.$ and $\left.45^{\circ} \mathrm{C}\right)$. We remind that, for a given temperature, the same metallization bath was used without bath renewing until the end of the experiment. The difference in color of the deposited copper layers in Figure 1 probably originated from the difference in the thickness and the irregularities of the copper layer which reflects the light differently.

At lower temperatures, the initiation of copper deposition was delayed compared to the higher bath temperatures. Nevertheless, the copper quantity was very similar after 60 minutes of deposition at $35{ }^{\circ} \mathrm{C}, 40^{\circ} \mathrm{C}$ and $45^{\circ} \mathrm{C}$, i.e. around $2.5 \mathrm{mg} \mathrm{cm}^{-2}$. The reaction continued and the deposited copper amount was even more important after $80 \mathrm{~min}$ at $35^{\circ} \mathrm{C}$ when compared to $40^{\circ} \mathrm{C}$ and $45^{\circ} \mathrm{C}$. Theoretically a mass gain of $1 \mathrm{mg} \mathrm{cm}^{-2}$ corresponds to a copper thickness of $1.12 \mu \mathrm{m}$ if the layer is uniform [34]. For the bath temperatures of $35^{\circ} \mathrm{C}, 40^{\circ} \mathrm{C}$ and $45^{\circ} \mathrm{C}$, after 1 hour, the copper layer thickness was around $2.8 \mu \mathrm{m}$.

The copper deposition rate calculated from Figure 2 by taking the first derivative of the curves with respect to time, considering a piecewise linear function shown in Figure 3. The deposition rate was not constant. Since the bath was not renewed during an experiment, the available copper ions in the metallization bath decreased due to its continuous consumption in time. The deposition rate curves displayed a maximum at around $50-70 \mu \mathrm{g} \mathrm{cm}^{-2} \mathrm{~min}^{-1}$. The maximum rate seemed to shift to longer metallization times when the bath temperature decreased. 
In the case of $55^{\circ} \mathrm{C}$, the deposition was very fast and took less than 15 minutes during which we could unfortunately have only very few experimental mass measurement points. This was the reason why the curves for $55^{\circ} \mathrm{C}$ was not represented in Figure 3 and Figure 6 as well as its SEM picture in Figure 4.

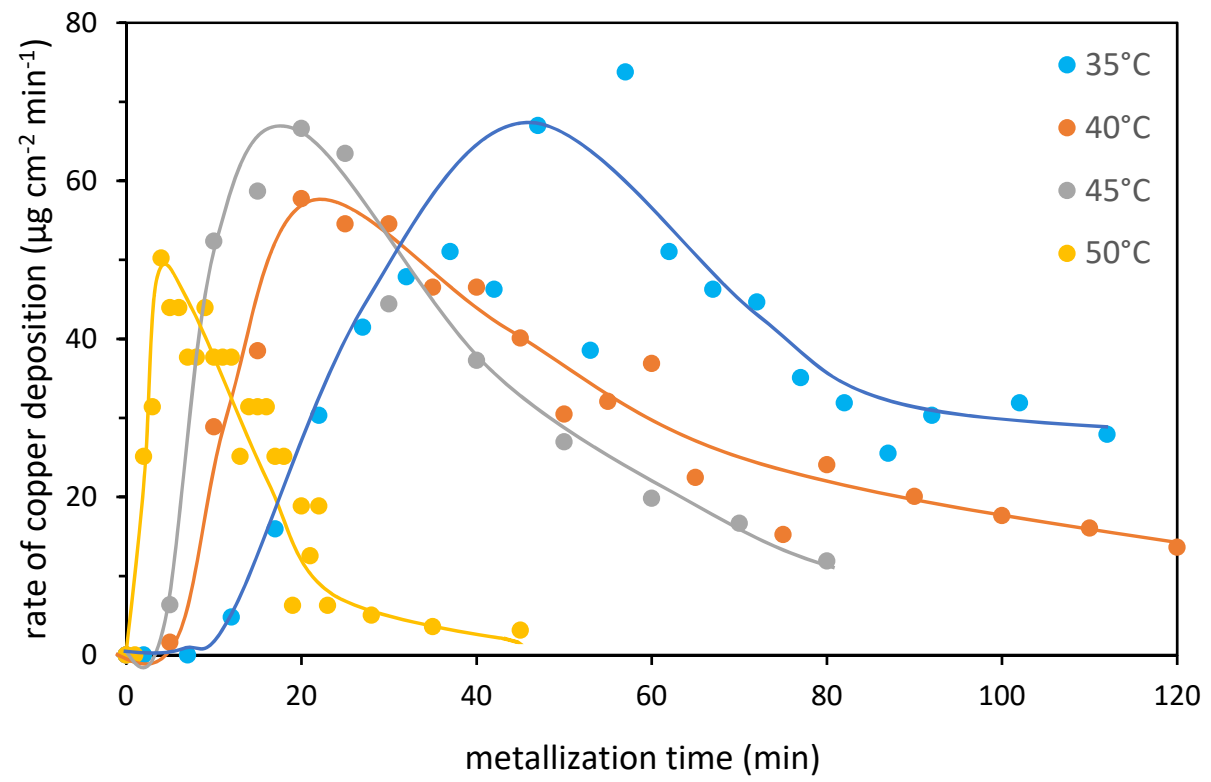

Figure 3. Rate of electroless Cu deposition on LCP-0.15 wt \% Pd for different metallization bath temperatures $\left(35^{\circ} \mathrm{C}, 40^{\circ} \mathrm{C}, 45^{\circ} \mathrm{C}\right.$ and $\left.50^{\circ} \mathrm{C}\right)$.

The copper layers deposited on LCP- $0.15 \mathrm{wt} \% \mathrm{Pd}$ at constant temperatures $\left(35^{\circ} \mathrm{C}, 40^{\circ} \mathrm{C}, 45^{\circ} \mathrm{C}\right.$ and $50^{\circ} \mathrm{C}$ ) were examined by SEM at the end of each experiment (Figure 4). The spherical particles were observed on all the surfaces. The size of copper particles seems to become smaller with increasing bath temperature since the SEM images were taken with the same magnification. As concluded from Figure 2, the higher the bath temperature (in the range of $35^{\circ} \mathrm{C}-55^{\circ} \mathrm{C}$ ), the lower the final deposited amount of copper on LCP-0.15 wt \% Pd sample surfaces on which the SEM observations were performed. 

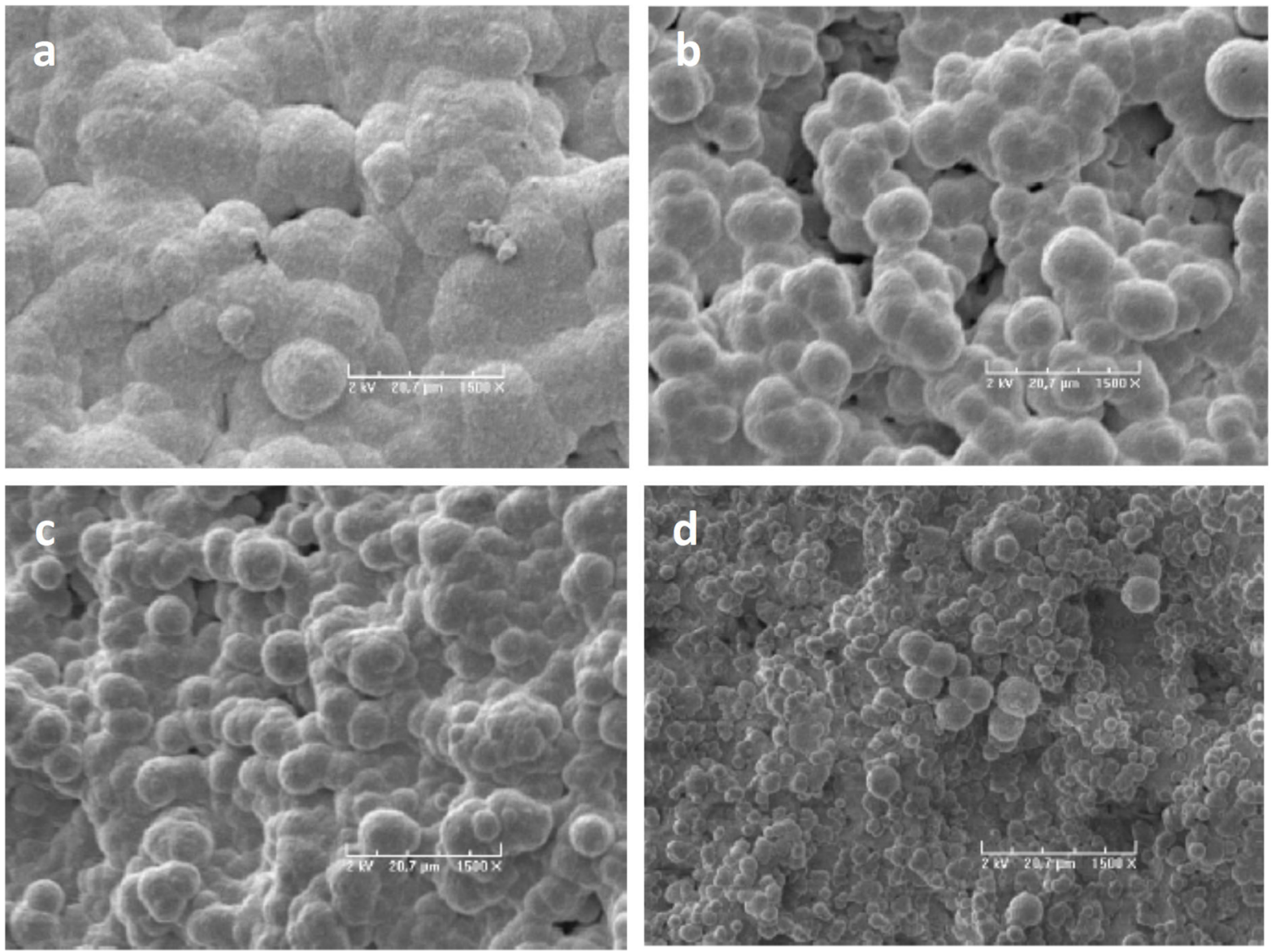

Figure 4. SEM observation of metallized copper layers on LCP-0.15 wt \% Pd at different temperatures of metallization: a) $35^{\circ} \mathrm{C}$, b) $40{ }^{\circ} \mathrm{C}$, c) $45^{\circ} \mathrm{C}$, d) $50^{\circ} \mathrm{C}$.

The diameter of the electroless deposited copper particles seems to obey a Gaussian distribution function as shown in Figure 5 (for example for a bath temperature of $40^{\circ} \mathrm{C}$ ) while the initial composition of metallization bath was kept constant. On Figure 5, the histogram represents the experimental probability density as a function of measured particle diameter with an interval of $1 \mu \mathrm{m}$ (0-1 $\mu \mathrm{m}, 1-2 \mu \mathrm{m}$, etc... with an average value of $0.5 \mu \mathrm{m}, 1.5 \mu \mathrm{m}$, etc. respectively). The scattered dots show the probability density against the measured particle diameter plotted by using a Gaussian distribution function and the continuous line is the full theoretical Gaussian function for guidance to the eye. 


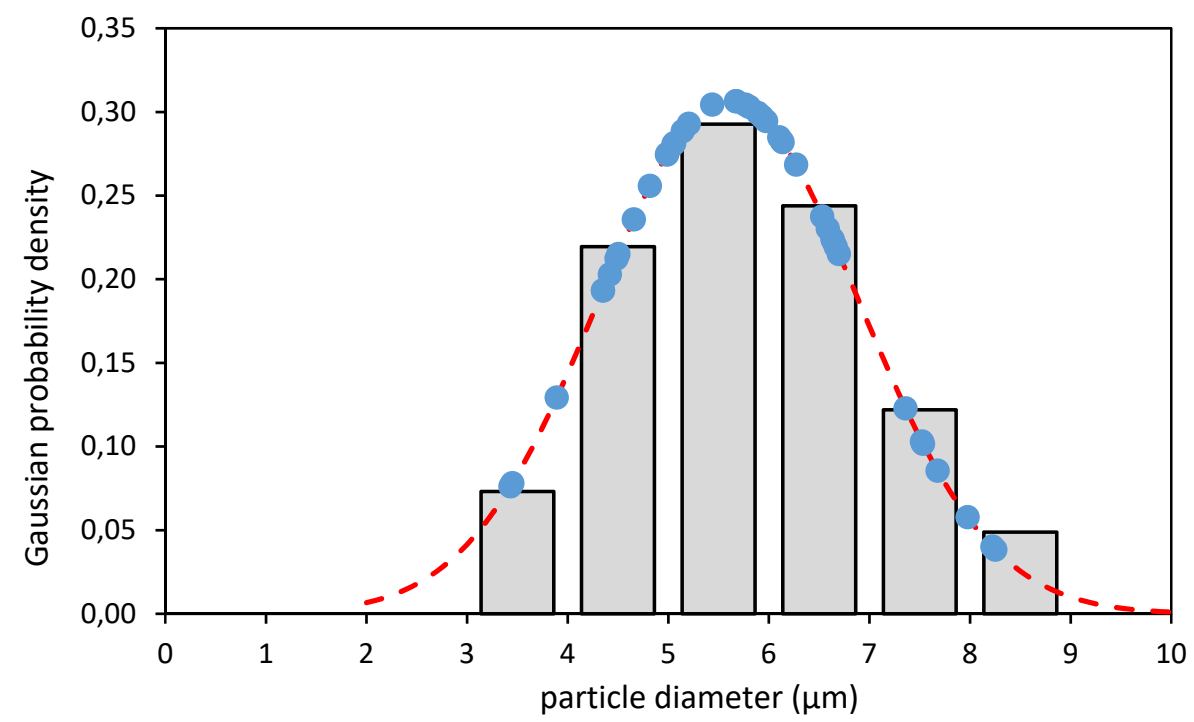

Figure 5. Probability density versus the diameter of copper particles deposited at $40{ }^{\circ} \mathrm{C}$ on LCP- 0.15 wt \% Pd sample.

In such a way, the copper particle diameter distribution was studied for different metallization bath temperatures (Figure 6) by keeping the initial bath composition constant. It appeared that the mean particle diameter shifted from around $8 \mu \mathrm{m}$ to $2 \mu \mathrm{m}$ and the distribution function curves were sharpened (standard deviation was twice at $35^{\circ} \mathrm{C}$ compared to $50^{\circ} \mathrm{C}$ ) with increasing bath temperature. We keep in mind that the initial bath composition was same for each temperature i.e. $40 \mathrm{~mL}$ of ENPLATE LDS Cu100, $160 \mathrm{~mL}$ of deionized water, and $2 \mathrm{~mL}$ of formaldehyde with a volume ratio of 20:80:1. 


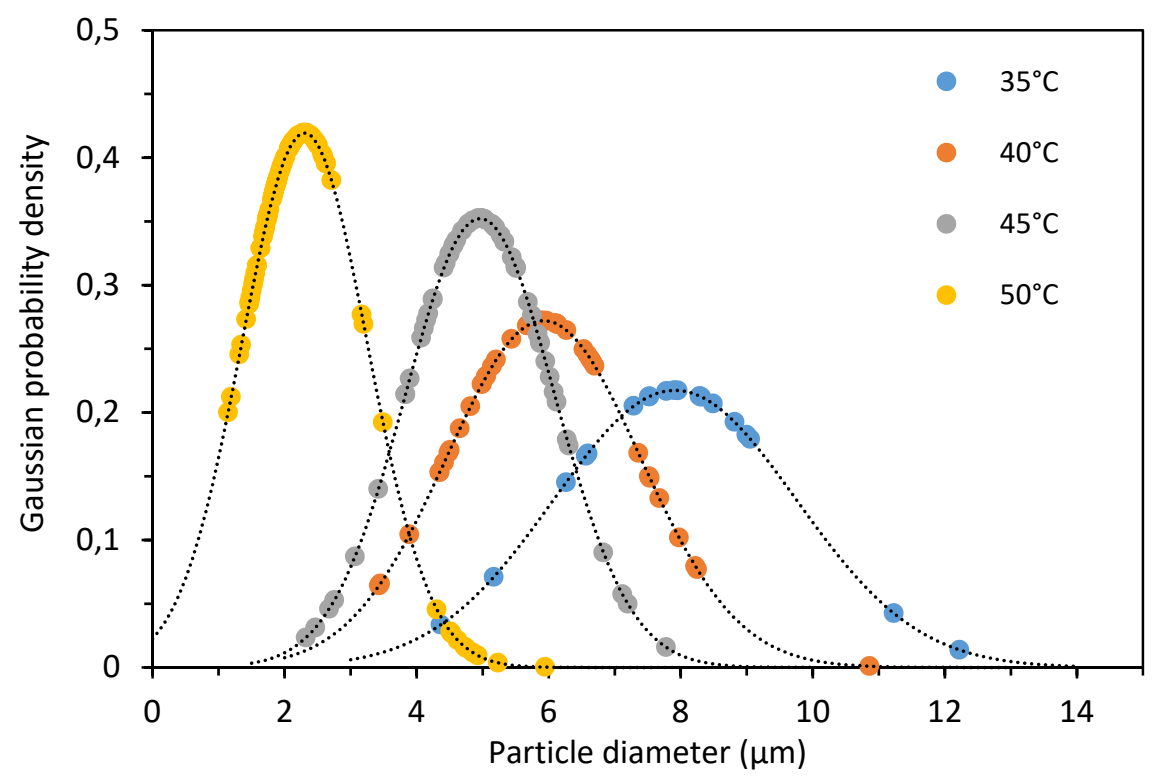

Figure 6. Distribution of copper particle diameter measured on the pictures in Figure 4 for different bath temperatures: $35^{\circ} \mathrm{C}, 40^{\circ} \mathrm{C}, 45^{\circ} \mathrm{C}$, and $50^{\circ} \mathrm{C}$ on LCP- 0.15 wt $\%$ Pd.

\section{Electroless copper deposition on LCP-0.15 wt\% Pd with different formaldehyde volume in the metallization bath at $45^{\circ} \mathrm{C}$}

The concentration of formaldehyde in the metallization bath can also affect the copper deposition process on LCP-0.15 wt \% Pd. Baths with different initial compositions were prepared while maintaining the metallization bath temperature at $45^{\circ} \mathrm{C}$. The formaldehyde volumes of $1 \mathrm{~mL}, 1.5 \mathrm{~mL}$, $2 \mathrm{~mL}$ and $6 \mathrm{~mL}$ were poured into baths including $160 \mathrm{~mL}$ of deionized water and $40 \mathrm{~mL}$ of ENPLATE LDS Cu100, i.e. the ENPLATE LDS Cu100, deionized water and formaldehyde with volume ratios of 20:80:0.5, 20:80:0.75, 20:80:1 and 20:80:3, respectively.

As shown in Figure 7, the LCP-0.15 wt \% Pd samples were metallized in these baths having different composition at $45^{\circ} \mathrm{C}$, which was the usually used bath temperature. The color of deposited layers was similar and had a typical metallic copper color. 


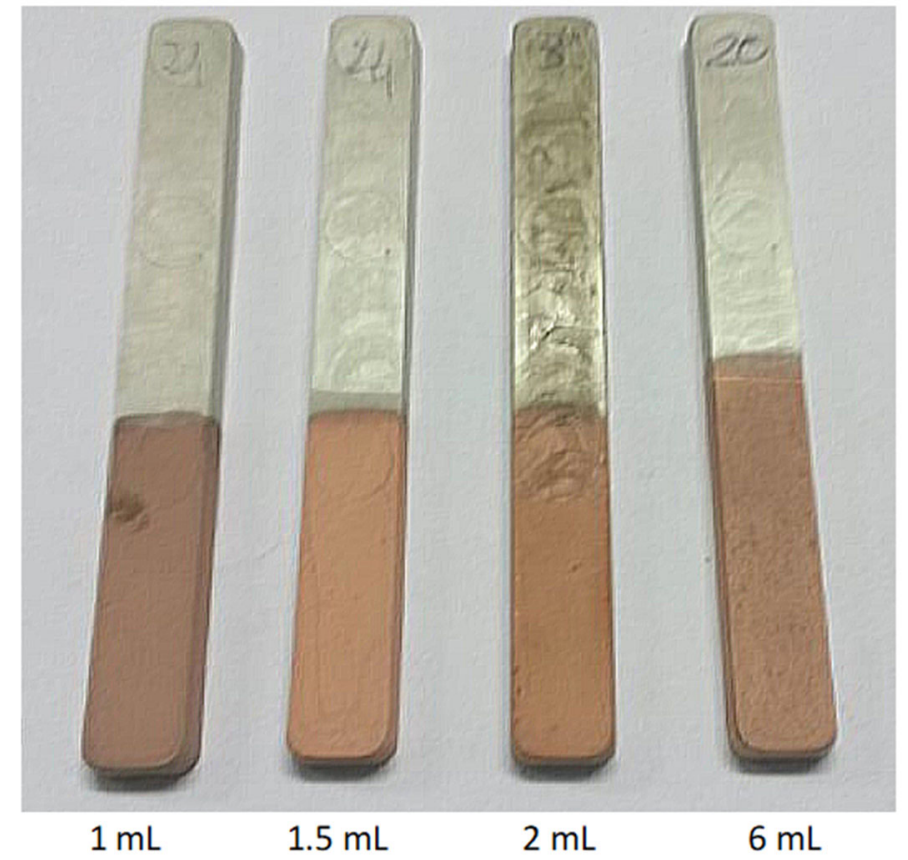

Figure 7. Electroless copper deposited LCP-0.15 wt \% Pd samples with different formaldehyde volume ( $1 \mathrm{~mL}, 1.5 \mathrm{~mL}, 2 \mathrm{~mL}$ and $6 \mathrm{~mL}$ ) in the metallization bath including $160 \mathrm{~mL}$ deionized water and $40 \mathrm{~mL}$ ENPLATE LDS Cu100. Bath temperature was $45^{\circ} \mathrm{C}$. The pictures were taken at the end of the metallization experiments.

The amount of deposited copper on LCP-0.15 wt \% Pd samples was plotted against cumulated dipping time in the metallization bath with different concentrations of formaldehyde. (Figure 8). 


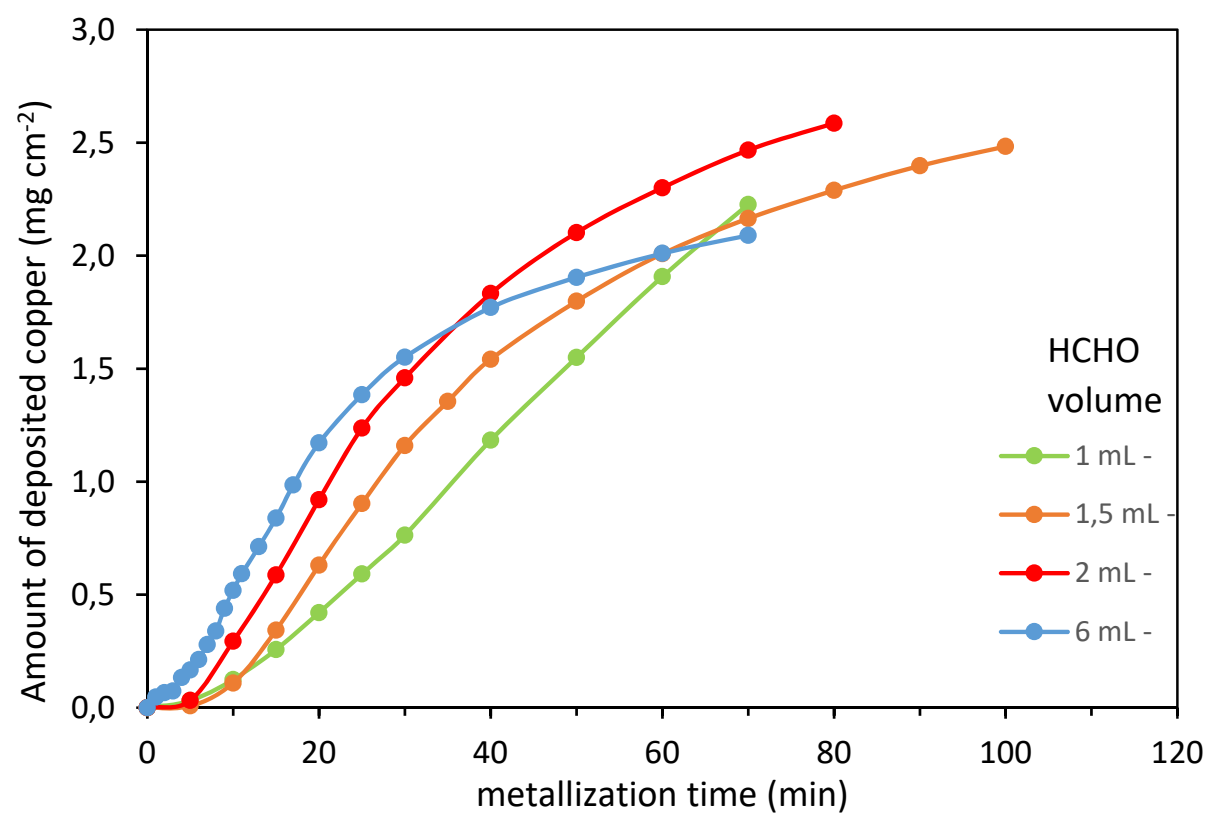

Figure 8. Evolution of copper amount deposited on LCP-0.15 wt \% Pd with different formaldehyde volumes ( $1 \mathrm{~mL}, 1.5 \mathrm{~mL}, 2 \mathrm{~mL}, 6 \mathrm{~mL})$ in the metallization bath kept at $45^{\circ} \mathrm{C}$.

The copper amount $\left(\mathrm{mg} \mathrm{cm}^{-2}\right)$ increased with cumulated dipping time for all metallization baths, regardless of the bath composition.

In the bath with the highest formaldehyde volume i.e. $6 \mathrm{~mL}$, the reaction seemed to initiate before all baths with lower formaldehyde volumes. After 60 minutes of deposition, the deposited Cu amount was around 2-2.5 $\mathrm{mg} \mathrm{cm}^{-2}$ and similar on all LCP-0.15 wt \% Pd samples.

As previously, the copper deposition rate was calculated by taking the first derivative of the curves with respect to time, considering a piecewise linear function and plotted as a function of dipping time for LCP-0.15 wt \% Pd samples (Figure 9). We remarked that the bath with the highest volume of formaldehyde $(6 \mathrm{~mL})$ has a highest maximum rate and the maximum rate occurs in a shorter metallization time. In the bath with the lowest formaldehyde volume, i.e. $1 \mathrm{~mL}$, the maximum deposition rate was the lowest, lying in a range between 35 to $40 \mu \mathrm{g} \mathrm{cm}^{-2} \mathrm{~min}^{-1}$ and seemed to be almost constant after 30-40 min of metallization time. 


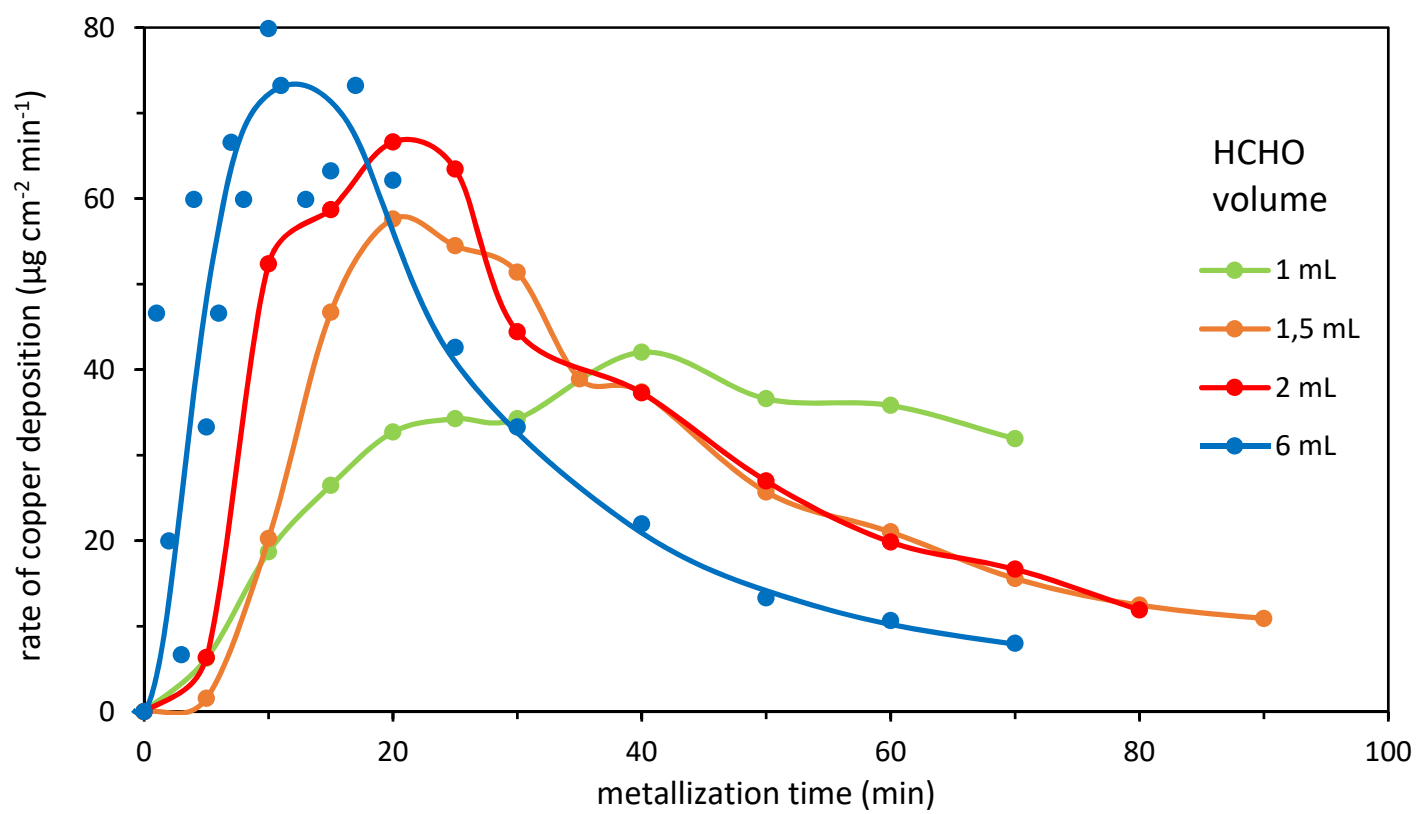

Figure 9. Rate of electroless Cu deposition on LCP-0.15 wt \% Pd for different initial formaldehyde volumes in the metallization bath. The bath temperature was kept at $45^{\circ} \mathrm{C}$.

The SEM observations were performed on copper layers deposited on LCP-0.15 wt \% Pd samples in the metallization baths with different formaldehyde volumes (Figure 10). 

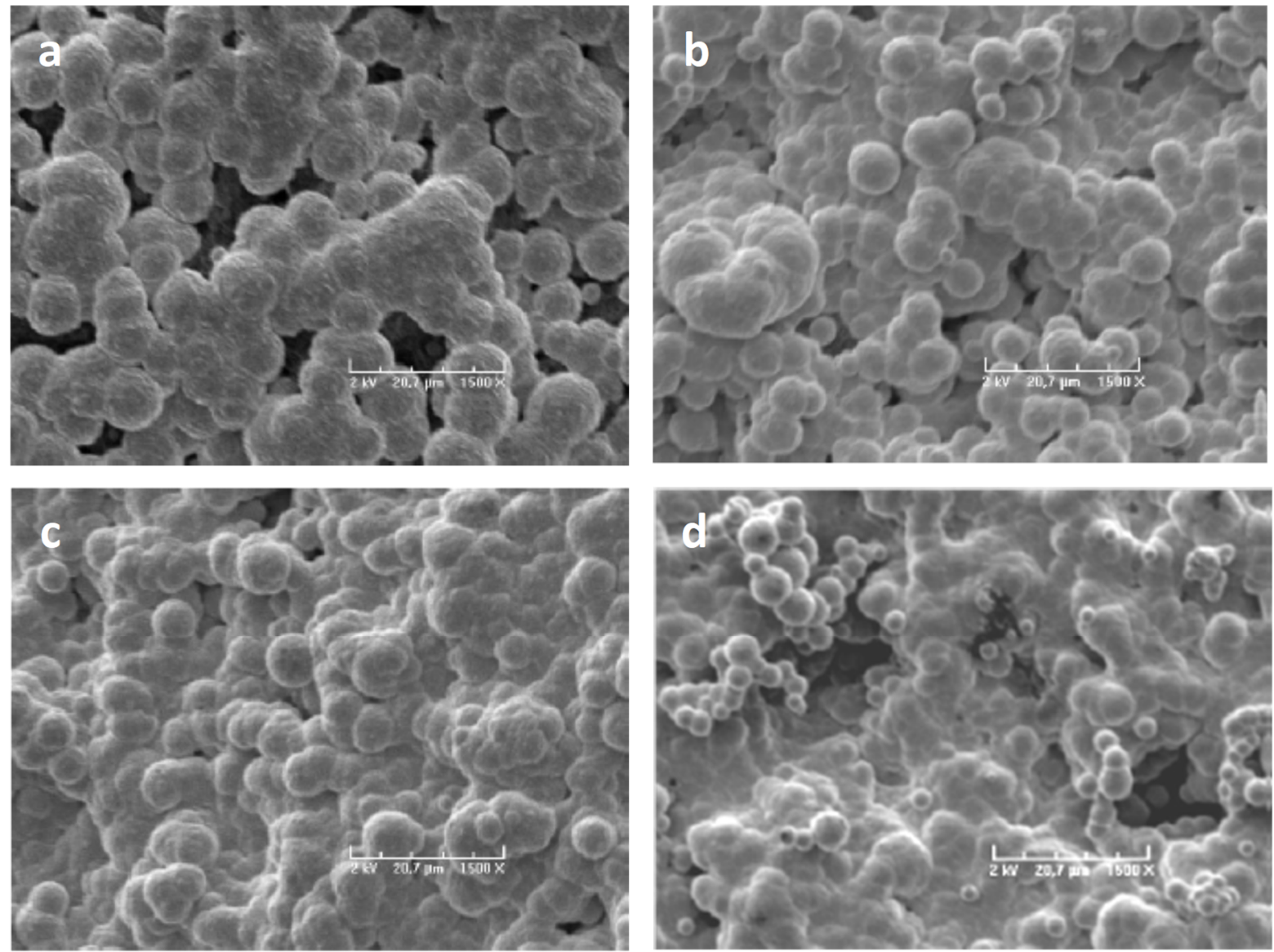

Figure 10. SEM observations on copper layers deposited on LCP-0.15 wt \% Pd samples in the metallization baths with different volumes of formaldehyde: a) $1 \mathrm{~mL}$, b) $1.5 \mathrm{~mL}$, c) $2 \mathrm{~mL}$, d) $6 \mathrm{~mL}$. The metallization baths were kept at a temperature of $45^{\circ} \mathrm{C}$.

The copper particle diameter distribution was studied by a Gaussian distribution function for different formaldehyde concentrations in the metallization bath (Figure 11). The mean copper particle diameter shifted to smaller values with increasing formaldehyde volume in the bath. The mean copper particle diameters were around $7 \mu \mathrm{m}$ and $5 \mu \mathrm{m}$ in metallization bath with $1 \mathrm{~mL}$ and 2 $\mathrm{mL}$ of formaldehyde, respectively, and decreased to around $3.9 \mu \mathrm{m}$ in the bath with $6 \mathrm{~mL}$ of $\mathrm{HCOH}$. The standard deviation increased from 0.96 to 1.4 with increasing formaldehyde concentration from $1 \mathrm{~mL}$ to $6 \mathrm{~mL}$, respectively. 


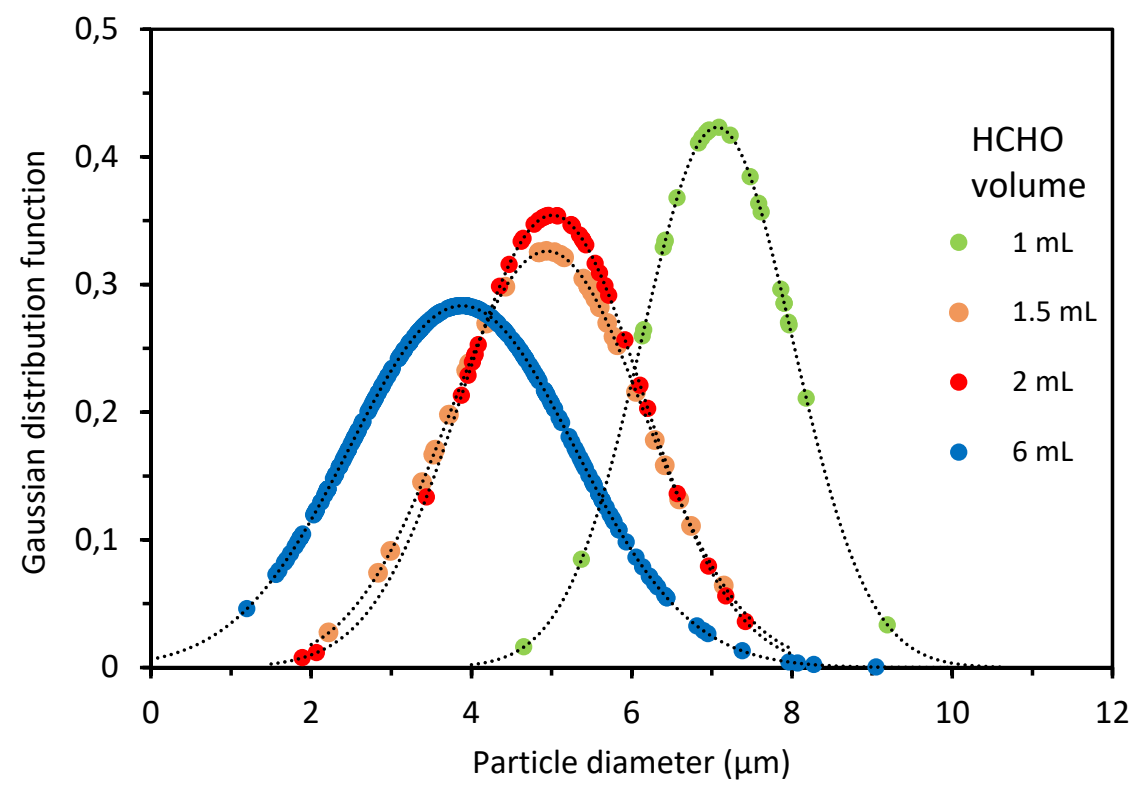

Figure 11. Copper particle size distributions deposited on LCP-0.15 wt \% Pd in the baths with different $\mathrm{HCHO}$ concentrations $\left(1 \mathrm{~mL}, 1.5 \mathrm{~mL}, 2 \mathrm{~mL}\right.$ and $6 \mathrm{~mL}$ ) in a metallization bath kept at $45^{\circ} \mathrm{C}$.

Since the bath temperature and formaldehyde concentration were varied separately by keeping one of them constant, we can estimate the activation energy of electroless copper deposition and the order of reaction with respect to formaldehyde. For electroless copper deposition in the presence of formaldehyde as reducing agent and EDTA as chelating agent, the overall copper deposition reaction takes place [1]:

$\mathrm{CuEDTA} \mathrm{A}^{2-}+2 \mathrm{HCHO}+4 \mathrm{OH}^{-} \rightarrow \mathrm{Cu}^{0}+\mathrm{H}_{2}+2 \mathrm{H}_{2} \mathrm{O}+2 \mathrm{HCOO}^{-}+\mathrm{EDTA}^{4-}$

The rate, $r$, that determines the kinetics of the electroless copper deposition can be written [38]:

$r=k\left[\mathrm{Cu}^{2+}\right]^{a}\left[\mathrm{OH}^{-}\right]^{b}[\mathrm{HCHO}]^{c}(\operatorname{LIGAND})^{d}$

where $\mathrm{k}$ is the temperature dependent rate constant and a, b, c, d are the orders of reaction.

For calculating the order of reaction with respect to the formaldehyde, only the formaldehyde concentration was varied ( $1 \mathrm{~mL}, 1.5 \mathrm{~mL}, 2 \mathrm{~mL}$ and $6 \mathrm{~mL}$ ) by keeping all other metallization bath 
components (deionized water and ENPLATE LDS Cu100 fixed to $160 \mathrm{~mL}$ and $40 \mathrm{~mL}$, respectively) and the bath temperature constant $\left(45^{\circ} \mathrm{C}\right)$.

The copper deposition rate would then be proportional to $\left[\mathrm{HCHO}^{c}\right.$ for a given temperature. We can then rewrite the equation (2)

$r=k^{\prime}[\mathrm{HCHO}]^{c}$

where $k^{\prime}$ is another rate constant including all constants in equation (2).

The plot of $\ln r$ as a function of $\ln [\mathrm{HCOH}]$ permitted to estimate the order of the reaction $\mathrm{c}$ with respect to formaldehyde for a given amount of deposited copper at $45^{\circ} \mathrm{C}$. The reaction order with respect to formaldehyde was around 0.6 at $0.2 \mathrm{mg} \mathrm{cm}^{-2}$ of deposited copper and decreased to 0.17 at $0.8 \mathrm{mg} \mathrm{cm}^{-2}$ (Figure 12).

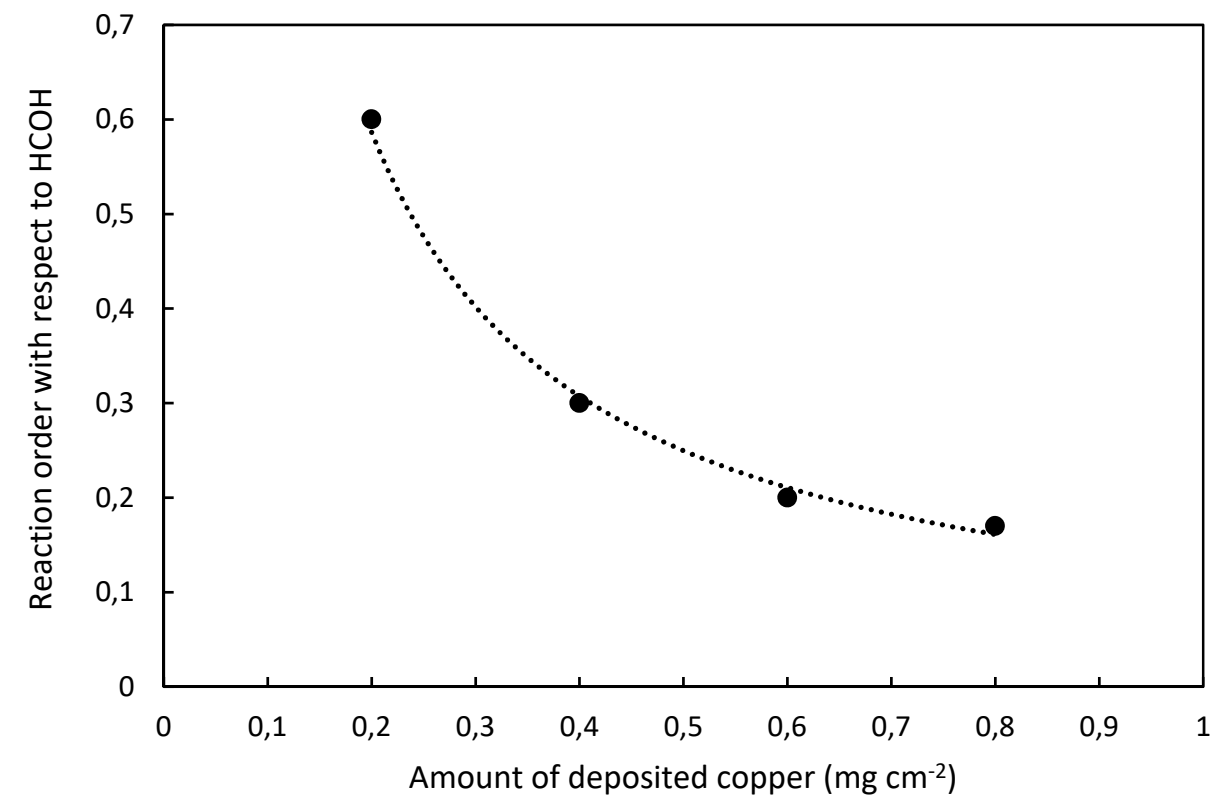

Figure 12. Evolution of the order of copper deposition reaction with respect to formaldehyde with deposited copper amount at $45^{\circ} \mathrm{C}$ on LCP- 0.15 wt \% Pd. 
Our results show that the order decreases from 0.6 to 0.2 with increasing amount of deposited copper from $0.2 \mathrm{mg} \mathrm{cm}^{-2}$ to $0.8 \mathrm{mg} \mathrm{cm}^{-2}$. It has been pointed out that the influence of formaldehyde concentration was generally small during steady state (final) deposition i.e. reaction orders less than 0.1 , however during initial stages, the reaction was found to be the first order with respect to formaldehyde [38]. The reaction order for formaldehyde has been reported 0.68 during the initial stage to 0 during the final stage [38]. Donahue and Shippey have found around 0.2 as the reaction order for formaldehyde [39]. Our results are in rather good agreement with the results found in the literature [38] [39].

The activation energy for electroless copper deposition was also estimated for different amounts of deposited copper on LCP-0.15 wt \% Pd samples, supposing that the rate equation obeys the Arrhenius law i.e. $k=A e^{-E / R T}$ in equation (2) where $\mathrm{A}$ is the pre-exponential factor, $\mathrm{E}$ is the activation energy, $\mathrm{R}$ and $\mathrm{T}$ are the universal gas constant and the temperature respectively. In our experiments, the bath temperature was changed from $35{ }^{\circ} \mathrm{C}$ to $55^{\circ} \mathrm{C}$ and the formaldehyde volume was kept constant at $2 \mathrm{~mL}$ in a bath of $160 \mathrm{~mL}$ of deionized water and $40 \mathrm{~mL}$ of ENPLATE LDC Cu100. The plot of $\ln k$ as a function of $1 / T$ permitted to estimate the activation energy for a given amount of electroless deposited copper. The variation of the activation energy with the amount of electroless deposited copper was shown in Figure 13. The activation energy decreased with increasing copper amount: around $45 \mathrm{~kJ} \mathrm{~mol}^{-1}$ for $0.2 \mathrm{mg} \mathrm{cm}^{-2}$ and around $26 \mathrm{~kJ} \mathrm{~mol}^{-1}$ for $0.4 \mathrm{mg} \mathrm{cm}^{-2}$ of deposited copper. 


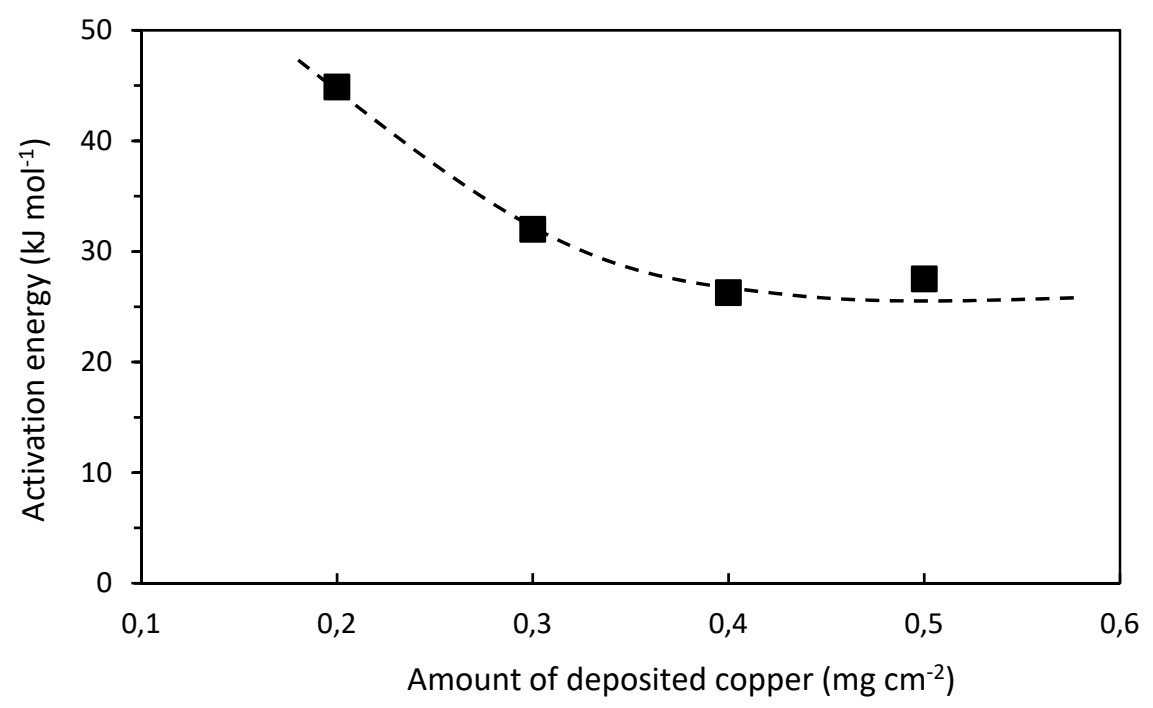

Figure 13. Activation energy of electroless copper deposition with different amounts of electroless deposited copper on LCP-0.15 wt \% Pd. The bath included ENPLATE LDC Cu100, deionized water and formaldehyde with a volume ratio of 20:80:1, respectively.

Several values of activation energy have been found in the literature [38]. Schumacher et al. have calculated an activation energy of $60.9 \mathrm{~kJ} \mathrm{~mol}^{-1}[40]$. This value was probably at the beginning of the deposition reaction since they have indicated that the reaction with respect to formaldehyde was the first order. For the electroless copper deposition process, an activation energy of $46 \mathrm{~kJ} \mathrm{~mol}^{-1}$ has also been reported by Molenaar et al. [41] in good agreement with our results.

The activation energies of $49-50 \mathrm{~kJ} \mathrm{~mol}^{-1}, 46 \mathrm{~kJ} \mathrm{~mol}^{-1}$ and $24 \mathrm{~kJ} \mathrm{~mol}^{-1}$ for the electroless copper process have been reviewed in the presence of $\mathrm{Cu}, \mathrm{Ni}$ and $\mathrm{Pd}$ catalysts respectively [35]. Nevertheless, the nature of the catalyst is only important until the catalyst is covered by copper. After the catalyst is covered by copper, the reaction becomes autocatalytic, which means the deposited copper acts as a catalyst for further plating. In theory, there is no limit to the thickness of grown copper layer. In practice, however, side reactions will eventually become dominant, and bath lifetime is finite. 
Our preliminary adhesion measurements determined from the pull up test by using a homemade device for sample holding on a tensile test machine resulted the stress values higher than $7 \mathrm{MPa}$ on copper layers deposited during 2 hours on LCP-0.15 wt \% Pd. The copper adhesion on LCP depends on the surface roughness [20], [42]. Ge et al. [42] have investigated the electroless copper deposition on the LCP films subjected to different surface treatments and measured a pull strength of around 5$7 \mathrm{MPa}$ for electroless copper layer deposited on untreated and treated LCP surfaces by different processes. Our preliminary adhesion values of electroless deposited copper on LCP-0.15 wt \% Pd are relatively high and are in line with those of Ge et al. [42]

\section{CONCLUSIONS}

The electroless copper deposition was studied on polymer samples prepared by the incorporation of a very small amount ( $<0.5 \mathrm{wt} \%)$ of metal-organic compounds (palladium acetate) into the molten LCP Vectra ${ }^{\circledR}$ E820i. During blending, palladium acetate is thermally decomposed leading to the metallic particles on which the electroless deposition of copper is triggered. After blending, the samples are shaped in an injection mold. The samples were then etched in a bath permitting to increase the roughness and improving the mechanical interlocking of the electroless deposited copper particles.

The electroless copper deposition was performed in a bath including a commercial copper salt solution and formaldehyde as reducing agent.

The influence of the metallization bath temperature and bath composition on the electroless copper deposition was studied on on LCP-0.15 wt \% Pd. For a fixed bath composition, the copper deposition was investigated at the temperature range of $35^{\circ} \mathrm{C}-55^{\circ} \mathrm{C}$. The formaldehyde concentration was also varied from $1 \mathrm{~mL}$ to $6 \mathrm{~mL}$ in the metallization baths including $40 \mathrm{~mL}$ of ENPLATE LDS100 and $160 \mathrm{~mL}$ of distilled water by keeping the bath temperature et $45^{\circ} \mathrm{C}$. When the bath composition was kept constant, the deposited copper amount increased with cumulative dipping time into the 
metallization bath for all studied temperatures but the final amount was very low at $50{ }^{\circ} \mathrm{C}$ and $55^{\circ} \mathrm{C}$ when compared to the deposition at $35{ }^{\circ} \mathrm{C}, 40{ }^{\circ} \mathrm{C}$ and $45{ }^{\circ} \mathrm{C}$. The deposition was also delayed at lower temperatures. After one hour of electroless deposition, the deposited copper amount was around $2.5 \mathrm{mg} \mathrm{cm}^{-2}$ and the maximum deposition rate was around $60 \mu \mathrm{g} \mathrm{cm}^{-2} \mathrm{~min}^{-1}$ for the deposition temperatures of $35^{\circ} \mathrm{C}, 40^{\circ} \mathrm{C}$ and $45^{\circ} \mathrm{C}$. The diameter of the deposited copper particles follows a Gaussian distribution function. The mean particle size and standard deviation decreased with increasing bath temperature. The influence of the formaldehyde concentration (volume: $1 \mathrm{~mL}$, $1.5 \mathrm{~mL}, 2 \mathrm{~mL}$ and $6 \mathrm{~mL}$ in a bath of around $200 \mathrm{~mL}$ ) was also studied on LCP- $0.15 \mathrm{wt} \%$ Pd by keeping the bath temperature constant at $45^{\circ} \mathrm{C}$. The deposition starts earlier in the baths with higher concentration of formaldehyde. The electroless deposited copper amount was similar after 60 minutes of deposition for all the baths, having different formaldehyde concentration. The maximum deposition rate was higher and situated at shorter time when the formaldehyde concentration is higher. The electroless deposited copper particles diameter obeys a Gaussian distribution. The mean particle diameter decreases but the standard deviation increases with increasing concentration of formaldehyde in the metallization bath on LCP-0.15 wt \% Pd.

The reaction order with respect to formaldehyde was calculated around 0.6 at $0.2 \mathrm{mg} \mathrm{cm}^{-2}$ of deposited copper and decreased to 0.17 for a deposited copper amount of $0.8 \mathrm{mg} \mathrm{cm}^{-2}$. The calculated activation energy for electroless copper deposition decreased with increasing deposited copper amount: around $45 \mathrm{~kJ} \mathrm{~mol}^{-1}$ for $0.2 \mathrm{mg} \mathrm{cm}^{-2}$ and around $26 \mathrm{~kJ} \mathrm{~mol}^{-1}$ for $0.4 \mathrm{mg} \mathrm{cm}^{-2}$ of copper. In summary, the influence of metallization bath parameters on the electroless copper deposition on LCP-0.15 wt \% Pd samples prepared by a simple and cheap method was studied in order to optimize the electroless copper deposition process on polymers. Bath temperature and formaldehyde concentration affect the electroless deposited copper amount, copper deposition rate and the copper particle diameter. 


\section{ACKNOWLEDGEMENTS}

We thank J. Sautel and G. Martin from Radiall S. A Company (Grenoble, France) for supplying us the commercial bath of Enplate Cu100 product. We gratefully express our gratitude to our students: A. Pion-Roux, D. Forgereau, G. Cappelli, C. Villemur, T. Raminosona, M. Lassara and J. Cretin for their contribution. 


\section{REFERENCES}

[1] K. L. Mittal, J. R. Susko, Metallized Plastics I : Fundamental and Applied Aspects, New York: Plenum Press, 1989.

[2] L. Ji, C. Wang, S. Wang, W. He, D. Xiao, Z. Tan , "Multiphysics coupling simulation of RDE for PCB manufacturing," Circuit World, vol. 41, no. 1, pp. 20-28, 2015.

[3] T. Zhang, "Fabrication and assembly of ultrathin flexible active printed circuits," PhD Thesis, Auburn University, 2006.

[4] M.M.R. Howlader, T. Suga, A. Takahashi, K. Saijo, S. Ozawa, K. Nanbu, "Surface activated bonding of LCP/Cu for electronic packaging," Journal of Materials Science, vol. 40, pp. 31773184, 2005.

[5] X. Wang, J. Engel, C. Liu, "Liquid Crystal Polymer (LCP) for MEMS: process and applications," J. Micromech. Microeng., vol. 13, pp. 628-633, 2003.

[6] M. Fahland, P. Karlsson, C. Charton, "Low resisitivity transparent electrodes for displays on polymer substrates," Thin Solid Films, vol. 392, p. 334, 2001.

[7] B. Wang, W. Eberhardt, H. Kück, "Adhesion of PVD layers on liquid crystal polymer pretreated by oxygen-containing plasma," Vacuum, vol. 79, pp. 29-133, 2005.

[8] M. Charbonnier, M. Romand, Y. Goepfert, D. Léonard, M. Bouadi , "Copper metallization of polymers by a palladium-free electroless process," Surf. Coatings Technol., vol. 200, p. 54785486, 2006.

[9] Y-C.Liao and Z-K. Kao, "Direct Writing Patterns for Electroless Plated Copper Thin Film on Plastic Substrates," ACS Appl. Mater. Interfaces, vol. 4, no. 10, p. 5109-5113, 2012.

[10] G.O. Mallory, J. B. Hadju, Electroless Plating : Fundamentals \& Applications, American Electroplaters and Surface Finishers Inc., 2009.

[11] K. Phasuksom, W. Prissanaroon-Ouajai, N. Brack and P. Pigram, "Electroless Copper Deposition on PET sheets," Advanced Materials Research, vol. 802, pp. 262-266, 2013.

[12] Y.C. Ee, Z. Chen, L. Chan, A. K.H. See, S.B. Law, K.C. Tee, K.Y. Zeng, L. Shen, "Effect of processing parameters on electroless Cu seed layer properties," Thin Solid Films, vol. 462 - 463, p. 197 201, 2004.

[13] S. Ghosh, "Electroless copper deposition: A critical review," Thin Solid Films, vol. 669, pp. 641658, 2019.

[14] M. Charbonnier, M. Alami, M. Romand, "Plasma treatment process for palladium for chemisorption onto polymers before electroless deposition," J. Electrochem Soc., vol. 143, pp. 472-480, 1996. 
[15] D. Nicolas-Debarnot, M. Pascu, C. Vasile, F. Poncin-Epaillard, "Influence of the polymer pretreatment before its electroless metallization," Surf. Coatings Techn., vol. 200, p. 4257-4265, 2006.

[16] H. Kupfer, G.R. Hecht, "Ecologically important metallization processes for high-performance polymers," Surface and Coatings Technology, vol. 112, p. 379, 1999.

[17] Z.J. Yu, E.T. Kang, K.G.Neoh , "Electroless plating of copper on polyimide films modified by surface grafting of tertiary and quaternary amines polymers," Polymer, vol. 43, p. 4137-4146, 2002.

[18] G.H. Yang, E.T. Kang, K.G. Neoh , "Electroless deposition of copper and nickel on poly(tetrafluoroethylene) films modified by single and double surface graft copolymerization," Applied Surface Science, vol. 178, pp. 165-177, 2001.

[19] Y. Lu , "Improvement of copper plating adhesion on silane modified PET film by ultrasonicassisted electroless deposition," Appl. Surf. Sci., vol. 256, p. 3554-3558, 2010.

[20] M. Zhou, W. Zhang, D. Ding, M. Li, "The effect of surface pretreatment on adhesive strength of Cu-plated liquid crystal polymer (LCP)," Applied Surface Science, vol. 258, pp. 2643-2647, 2012.

[21] Y. Li, Q. Lu, X. Qian, Z. Zhu, J. Yin, "Preparation of surface bound silver nanoparticles on polyimide by surface modification method and its application on electroless metal deposition," Appl. Surf. Sci., vol. 233, pp. 299-306, 2004.

[22] B. Girginer , B. Karagoz , M. Urgen , N. Bicak, "A method for polyaniline coatings on solid polystyrene surfaces and electroless copper deposition," Surf. Coatings Technol., vol. 202, p. 4176-4182, 2008.

[23] K. Kordás, S. Leppävuori, A. Uusimäki, T. F. George, L. Nánai, R. Vajtai, K. Bali, J. Békési, "Palladium thin film deposition on polyimide by CW Ar+ laser radiation for electroless copper plating," Thin solid Films, vol. 384, pp. 185-188, 2001.

[24] L. Naruškevičius , L. Tamašauskaitè-Tamašiūnaitè, A. Žielienè, V. Jasulaitienè, "A Co-based surface activator for electroless copper deposition," Surf. Coatings Technol., vol. 206, p. 29672971, 2012.

[25] E. Uzunlar, Z. Wilson, P. A. Kohl , "Electroless Copper Deposition Using Sn/Ag Catalyst on Epoxy Laminates," J. Electrochem. Soc., vol. 160, p. D3237-D3246, 2013.

[26] C-L. Lee, C-C. Syu, H-P. Chiou, C-R. Liu, C-H. Huang, "Effect of electrochemical surface area on electroless copper deposition: Pd nanocubes as new activators," Electrochim. Acta., vol. 59, p. 587-591, 2012.

[27] Y-H. Chang, C-C. Wan, Y-Y.Wang, "Formation of Pd catalyst by Nd:YAG laser irradiation for electroless copper deposition," Microelectron. Eng., vol. 87, pp. 2110-2114, 2010.

[28] J.H. Byeon, Y-W. Kim, "Ultrasound-assisted copper deposition on a polymer membrane and application for methanol steam reforming," Ultrason. Sonochem., vol. 20, p. 472-477, 2013. 
[29] D.I. Petukhov, M. N. Kirikova, A. A. Bessonov, M. J. A. Bailey, "Nickel and copper conductive patterns fabricated by reactive inkjet printing with electroless plating," Materials Letters, vol. 132, pp. 302-306, 2014.

[30] W. Wang , S. Ji , I. Lee , "A facile method of nickel electroless deposition on various neutral hydrophobic polymer surfaces," Applied Surface Science, vol. 283, pp. 309-320, 2013.

[31] J. Huang, C. Tian, J. Wang, J. Liu, Y. Li, Y. Liu, Z. Chen, "Fabrication of selective electroless copper plating on PET sheet: Effect of PET surface structure on resolution and adhesion of copper coating," Applied Surface Science, vol. 458, p. 734-742, 2018.

[32] S. J. Park, T-J. Ko, J. Yoon, M-W. Moon, K. H. Oh, J. H. Han, "Copper circuit patterning on polymer using selective surface modification and electroless plating," Applied Surface Science, vol. 396, p. 1678-1684, 2017.

[33] R. Zhou, T. Huang, L. Chen, S. Chen, S. Lin and Y. Zhuo, "Electroless Deposition of Confined Copper Layers Based on Selective Activation by Pulsed Laser Irradiation," Journal of Laser Micro/Nanoengineering, vol. 12, no. 2, p. 169, 2017.

[34] A. Atli, S. Simon, F.J. Cadete Santos Aires, L. Cardenas, E. Ehret, P. Lourdin , "A new strategy to activate liquid crystal polymer samples for electroless copper deposition," Journal of Applied Polymer Science, vol. 134, p. 44397, 2017.

[35] D.H. Redinger , Ph.D. Thesis, Solution Processing Techniques for Low-Cost Circuit Fabrication, University of California at Berkeley, 2007.

[36] "Celanese," [Online]. Available: https://www.celanese.com. [Accessed 172019 ].

[37] P. K.Gallagher, M. E. Gross, "The thermal decomposition of palladium acetate," J. Therm. Anal. , 31, vol. 31, pp. 1231-1241, 1986.

[38] P. Bindra and J. R. White, "Chapter 12 : Fundamental Aspects of Electroless Copper Plating," in Electroless Plating, Fundamentals \& Applications, G. O. Mallory and J. B.Hadju, Eds., American Electroplaters and Surface Finishers Society Inc., 2009, p. 289.

[39] F. M. Donahue, F. L.Shippey, Plating, vol. 60, p. 135, 1973.

[40] R. Schumacher, J. J. Pesek and O. R.Melroy, "Kinetic analysis of electroless deposition of copper," Journal of Physical Chemistry, vol. 89, no. 20, p. 4338- 4342, 1985.

[41] A. Molenaar, M. F. E. Holdrinet and L. K. H. van Beek, Plating, vol. 61, p. 238, 1974.

[42] J. Ge, M.P.K. Turunen, J.K. Kivilahti, "Surface modification of a Liquid-Crystalline Polymer for copper Metallization," J. Polym. Sci.: Part B: Poly. Phys., vol. 41, pp. 623-636, 2003.

[43] S. D. Gates, T. N. Blanton and T. G. Fawcett, "A new "chain" of events: polymers in the Powder Diffraction File (PDF ${ }^{\circledR}$ )," Powder Diffraction, vol. 29, no. 2, pp. 102-107, 2014.

[44] Y. Lu, L. Xue, F. Li, "Adhesion enhancement between electroless nickel and polyester fabric by a palladium-free process," Applied Surface Science, vol. 257, p. 3135-3139, 2011. 
[45] K. L. Parry, A. G. Shard, R. D. Short, R. G. White, J. D. Whittle, A. Wright, "ARXPS characterisation of plasma polymerised surface chemical gradients," Surface and Interface Analysis, vol. 38, no. 11, pp. 1497-1504, 2006.

[46] E. Ehret, E. Beyou, G. V. Mamontov, T. A. Bugrova, S. Prakash, M. Aouine, B. Domenichini, F. Cadete Santos Aires, "Bimetallic PdAg nanoparticle arrays from monolayer films of diblock copolymer micelles," Nanoscale, vol. 7, pp. 13239-13248, 2015.

[47] H. Ko, J. Jhin, D. Byun, J. Lee and D. Park, "Copper Thin Films on PET Prepared at Ambient Temperature by ECR-CVD," IEEE Transactions on Components and Packaging Technologies, vol. 28, no. 4, p. 781, 2005.

[48] S.C. Domenech, V.L.S. Severgnini, E.A. Pinheiro, A.O.V. Avila, N.G. Borges, E. Lima, V. Drago, V. Soldi , "Effect of chemical surface treatment on thermal stability of poly(ethylene terephthalate) films used in flexible circuits," Polymer Degradation and Stability, vol. 88, pp. 461-467, 2005.

[49] Y. Sung, Y. H. Chou, W. H. Hwu, Y. C. Fan, J. L. Cheng, M. D. Ger, "Electroless copper deposition by non-isothermal deposition technology," Mater. Chem. Phys., vol. 113, pp. 303-308, 2009.

[50] E. D. Giol, S. van Vlierberghe, R. E. Unger, D. Schaubroeck, H. Ottevaere, H. Thienpont, C. J. Kirkpatrick and P. Dubruel, "Endothelialization and Anticoagulation Potential of SurfaceModified PET Intended for Vascular Applications," Macromol. Biosci., p. 1800125, 2018.

[51] I. Youssef, S. Sall, T. Dintzer, S. Labidi, C.Petit, "Forward looking analysis approach to assess Copper acetate thermal decomposition Reaction Mechanism," American Journal of Analytical Chemistry, vol. 10, no. 5, pp. 153-170, 2019.

[52] J. Hu, C. Yin, H-Q. Mao, K. Tamada and W. Knoll , "Functionalization of Poly(ethylene terephthalate) Film by Pulsed Plasma Deposition of Maleic Anhydride," Adv. Funct. Mater., vol. 13, no. 9, pp. 692-697, 2003.

[53] K. L. Jarvis, P. J. Evans, "Growth of thin barrier films on flexible polymer substrates by atomic layer deposition," Thin Solid Films, vol. 624, pp. 111-135, 2017.

[54] S. J. Park, T-J. Kob, J. Yoon, M-W. Moon, K. H. Oh, J. H. Han, "Highly adhesive and high fatigueresistant copper/PET flexible electronic substrates," Applied Surface Science, vol. 427, p. 1-9, 2018.

[55] J. Compton, D. Thompson, D. Kranbuehl, S. Ohl, O. Gain, L. David, E. Espuche, "Hybrid films of polyimide containing in situ generated silver or palladium nanoparticles: Effect of the particle precursor and of the processing conditions on the morphology and the gas permeability," Polymer, vol. 47, p. 5303, 2006.

[56] E. Espuche, L.C. David, J. L. Afeld, J. M. Compton, D. W. Thompson, D. E. Kranbuehl, "In situ generation of nanoparticulate lanthanum(III) oxide-polyimide films: characterization of nanoparticle formation and resulting polymer properties," Polymer, vol. 46, pp. 6657-6665, 2005. 
[57] K. Woo, D. Kim, J.S. Kim, S. Lim, J. Moon, "Ink-jet printing of Cu-Ag based highly conductive tracks on a transparent substrate," Langmuir, vol. 25, no. 1, p. 429-433, 2009.

[58] S.M. Pelagade, N.L. Singh, A. Qureshi, R.S. Rane, S. Mukherjee, U.P. Deshpande, V. Ganesan, T. Shripathi, "Investigation of surface properties of Ar-plasma treated polyethylene terephthalate (PET) films," Nuclear Instruments and Methods in Physics Research B, vol. 289, p. 34-38, 2012.

[59] J. Hong, G. Guo, K. Zhang, "Kinetics and mechanism of non-isothermal dehydration of nickel acetate tetrahydrate in air," J. Anal. Appl. Pyrolysis, vol. 77, p. 111-115, 2006.

[60] V. Shabafrooz, M. Allahkarami, S. Bandla and J. C. Hanan , "Measuring Thermal Crystallinity in PET," in ANTEC, Society of Plastics Engineers-SPE, Indianapolis, 2016.

[61] T. Duguet, F. Senocq, L. Laffont, C. Vahlas, "Metallization of polymer composites by metalorganic chemical vapor deposition of $\mathrm{Cu}$ : Surface functionalization driven films characteristics," Surface and Coatings Technology, vol. 230, pp. 254-259, 2013.

[62] L. A. Baldenegro-Perez, D. Navarro-Rodriguez, F. J. Medellin-Rodriguez, B. Hsiao, C. A. AvilaOrta, and I. Sics, "Molecular Weight and Crystallization Temperature Effects on Poly(ethylene terephthalate) (PET) Homopolymers, an Isothermal Crystallization Analysis," Polymers, vol. 6, pp. 583-600, 2014.

[63] C. Radheshkumar, H. Münstedt, "Morphology and mechanical properties of antimicrobial polyamide/silver composites," Mater Letters, vol. 59, pp. 1949-1953, 2005.

[64] N. Krstulović, I. Labazan, S. Milošević, U. Cvelbar, A. Vesel and M. Mozetič, "Optical emission spectroscopy characterization of oxygen plasma during treatment of a PET foil," J. Phys. D: Appl. Phys., vol. 39, no. 17, p. 3799-3804, 2006.

[65] P. Holubar, M. Jilek, M.Sima, "Present and possible future applications of superhard nanocomposite coatings," Surf. Coat. Technol., vol. 133, p. 145, 2000.

[66] F. Awaja, D. Pavel , "Recycling of PET," European Polymer Journal, vol. 41, p. 1453-1477, 2005.

[67] E. Gonzalez, M. D. Barankin, P. C. Guschl and R. F. Hicks, "Remote Atmospheric-Pressure Plasma Activation of the Surfaces of Polyethylene Terephthalate and Polyethylene Naphthalate," Langmuir, vol. 24, pp. 12636-12643, 2008.

[68] J. Cao, Z. Wua, J. Yang, S. Li, H. Tang, G. Xie, "Site-selective electroless plating of copper on a poly(ethylene terephthalate) surface modified with a self-assembled monolayer," Colloids and Surfaces A: Physicochem. Eng. Aspects, vol. 415, p. 374- 379, 2012.

[69] C. Contini, M. G. Katsikogianni, F. T. O’Neill, M. O'Sullivan, F. Boland, D. P. Dowling, F. J. Monahan, "Storage Stability of an Antioxidant Active Packaging Coated with Citrus Extract Following a Plasma Jet Pretreatment," Food Bioprocess Technol, 2013.

[70] E. Cano, J. M. Bastidas, J. L. Polo and N. Mora, "Study of the Effect of Acetic Acid Vapor on Copper Corrosion at 40 and $80 \%$ Relative Humidity," Journal of The Electrochemical Society, vol. 148, no. 11, pp. B431-B437, 2001. 
[71] Z. Lin, D. Han, S. Li, "Study on thermal decomposition of copper(II) acetate monohydrate in air," J. Therm. Anal. Calorim., vol. 107, p. 471-475, 2012.

[72] J. Wang, C.J. Pan, N. Huang, H. Sun, P. Yang, Y.X. Leng, J.Y. Chen, G.J. Wan, P.K. Chu, "Surface characterization and blood compatibility of poly(ethylene terephthalate) modified by plasma surface grafting," Surface \& Coatings Technology, vol. 196, p. 307 - 311, 2005.

[73] M.H. Struszczyk, P. Bednarek, K. Raczynski, "Synthetic vascular prostheses," Polim Med., vol. 32, no. 1-2, pp. 13-22, 2002.

[74] K. Zhang, J. Hong, G. Cao, D. Zhan, Y. Tao, C. Cong, "The kinetics of thermal dehydration of copper(II) acetate monohydrate in air," Thermochimica Acta, vol. 437, no. 1-2, pp. 145-149, 2005.

[75] J. C. De Jesus, I. Gonzalez, A. Quevedo, T. Puerta, "Thermal decomposition of nickel acetate tetrahydrate: an integrated study by TGA, QMS and XPS techniques," Journal of Molecular Catalysis A: Chemical, vol. 228, p. 283-291, 2005.

[76] S. A. Jabarin and E. A. Lofgren, "Thermal Stability of Polyethylene Terephthalate," Polym Eng Sci., vol. 24, no. 13, pp. 1056-1063, 1984.

[77] J.V. Bellini, R. Machado, M.R. Morelli, R.H.G.A. Kiminami, "Thermal, Structural and Morphological Characterisation of Freeze-dried Copper(II) Acetate Monohydrate and its Solid Decomposition Products," Materials Research, vol. 5, no. 4, pp. 453-457, 2002.

[78] S. Ben Amor, M. Jacquet, P. Fioux, M. Nardin, "XPS characterisation of plasma treated and zinc oxide coated PET," Applied Surface Science, vol. 255, p. 5052-5061, 2009.

[79] A. Vesel, M. Mozetic, A. Zalar, "XPS study of oxygen plasma activated PET," Vacuum, vol. 82, p. 248-251, 2008.

[80] T. Blanton, "International Center for Diffraction Data (ICDD)," [Online]. Available: http://www.icdd.com/profile/march14files/plenary/Blanton.pdf. [Accessed 23 august 2018].

[81] J. P. Jog, "Crystallization of Polyethyleneterephthalate," Journal of Macromolecular Science, Part C, Polymer Reviews, vol. 35, no. 3, pp. 531-553, 1995.

[82] S. M. Rossnagel, "Directional and ionized physical vapor deposition for microelectronics applications," J. Vac. Sci. Technol., B, vol. 16, p. 2585, 1998.

[83] Y. Lu, L. Xue, F. Li, "Silver nanoparticle catalyst for electroless Ni deposition and the promotion of its adsorption onto PET substrate," Surface and Coating Technology, vol. 205, pp. 519-524, 2010.

[84] M. Fujiwara, T. Matsushita, S. Ikeda, "X-Ray Photoelectron Spectroscopy of Copper(II) Complexes with Donor Sets of O4, N2O4, N2O2, N4, N2S2, and S4," Analytical Sciences, vol. 9, pp. 289-291, 1993. 
[85] P. Roura, J. Farjas, H. Eloussifi, L. Carreras, S. Ricart, T. Puig, X. Obradors, "Thermal analysis of metal organic precursors for functional oxide preparation : Thin films versus powders," Thermochimica Acta , vol. 601, pp. 1-8, 2015.

[86] M.D. Judd, B.A. Plunkett, M.I. Poepe, "The thermal decomposition of calcium, sodium, silner and copper (II) acetates," J. of Ther. Anal., vol. 6, pp. 555-563, 1974.

[87] S.A.A. Mansour, "Thermoanalytical investigations of the decompostion course of copper oxysalts III. Copper (II) acetate monohydrate," J. of Therm. Anal., vol. 46, pp. 263-274, 1996.

[88] A. Y Obaid, A. O. Alyoubi, A. A. Samarkandy, S. A. Al-Thabaiti, S. S. Al-Juaid, A. A. El-Bellihi \& ElH. M. Deifallah, "Kinetics of Thermal Decomposition of Copper(II) Acetate Monohydrate," Journal of Thermal Analysis and Calorimetry, vol. 61, p. 985-994, 2000.

[89] Sagar K. Nayak, S. Mohanty, Sanjay K. Nayak, "Decomposed Copper(II) acetate over expanded Graphite (EG) as hybrid filler to fabricate epoxy based Thermal interface materials (TIMs)," Journal of Electronic Materials, vol. 49, p. 34-47, 2020.

[90] J. A. Rudd, D. R. Jones, C. W. Dunnill, and E. Andreoli, "Study of copper(II) oxide and copper(II) acetate on multiwalled carbon nanotubes by XPS," Surface Science Spectra, vol. 26, p. 014013, 2019.

[91] J. Jang, S. Chung, H. Kang, V. Subramanian, "P-type CuO and Cu2O transistors derived from solgel copper (II) acetate monohydrate precursor," Thin Solid Films, vol. 600, pp. 157-161, 2016.

[92] D. Tahir, S. Tougaard, "Electronic and optical properties of $\mathrm{Cu}, \mathrm{CuO}$ and $\mathrm{Cu} 2 \mathrm{O}$ studied by electron spectroscopy," J. Phys: Condens. Matter, vol. 24, p. 175002, 2012.

[93] J.E. McIntyre, "The historical development of Polyesters," in Modern Polyesters: Chemistry and Technology of Polyesters and Copolyesters, J. S. a. T. E. Long, Ed., John Wiley \& Sons, Ltd,, 2003, pp. 4-28.

[94] A. D. Padsalgikar, "Speciality Plastics in Cardiovascular Applications," in Plastics in Medical Devices for Cardiovascular Applications, William Andrew Publishing, 2017, pp. 53-82.

[95] M. Afzal, P.K. Butt, H. Ahmad, "Kineticks of thermal decomposition of metal acetates," J. of Therm. Analy., vol. 37, pp. 1015-1023, 1991. 